\title{
Filosofía del medioambiente y dignidad ¿por qué llamar a nuestra cultura a una conversión ecológica?
}

Ricardo Andrés Chavarriaga Tróchez

Universidad Industrial de Santander, Colombia

(c) $\underset{\mathrm{Br}}{\mathrm{i}}$ 


\title{
Filosofía del medioambiente y dignidad ${ }^{\star}$ ¿por qué llamar a nuestra cultura a una conversión ecológica?
}

Resumen: este ensayo es una proposición filosófica para una conversión ecológica dentro de tres puntos de apoyo: Una nueva religiosidad ambiental, una ética del cuidado y la alteridad humana. El artículo allegado propone el cambio de actitud frente a la naturaleza, pues una gran parte de la humanidad ha perdido la comunión con la naturaleza, y ha cambiado su imagen del mundo, al cual trata como un ente para el uso y el desperdicio. En ese sentido, la conversión ecológica amerita salir de la mentalidad colonial y volver a entender que no es posible cultura sin naturaleza.

Palabras clave: mundo, religión, alteridad, otro, libertad.

\section{Philosophy of the environment and dignity why call our culture to an ecological conversion?}

\begin{abstract}
: this academic paper is a philosofical proposition for an ecological conversion with the support of: A new environmental religiosity, an ethic of care and human alterity as reason of ends and not means. The article suggests the change of attitude towards nature, because a large part of humanity has lost communion with nature, and has changed its image of the world, which it treats as an entity for use and waste.
\end{abstract}

Keywords: World, Religion, otherness, other, freedom.

Fecha de recepción: 30 de octubre de 2016

Fecha de aceptación: 21 de agosto de 2017

Forma de citar (APA): Chavarriaga, R. (2018). Filosofía del medioambiente y dignidad ipor qué llamar a nuestra cultura a una conversión ecológica? Revista Filosofía UIS, 17(1), doi: http://dx.doi.org/10.18273/revfil.v17n1-2018015

Forma de citar (Harvard): Chavarriaga, R. (2018). Filosofía del medioambiente y dignidad ipor qué llamar a nuestra cultura a una conversión ecológica? Revista Filosofía UIS, 17(1), 317-325.

Ricardo Andrés Chavarriaga Tróchez: colombiano. Abogado y magíster en Filosofía, Universidad Industrial de Santander.

Correo electrónico: ricardoandres.chavatro@gmail.com

*Artículo de revisión. 


\section{Filosofía del medioambiente y dignidad ¿por qué llamar a nuestra cultura a una conversión ecológica?'}

La vida humana actúa en el mundo y tiene un propósito racional, además tiene diferentes facetas y modos de presentarse en la existencia y frente al entorno natural; tiende a crecer, moverse, reaccionar y relacionarse con otras vidas humanas y no humanas. Dependiendo de cómo se afiancen los movimientos de la existencia de cada uno se puede observar una ubicación ontológica de alteridad o de totalidad, una racionalidad es de medios o de fines, una práctica centrada en la dignidad o en el utilitarismo.

El sistema racional de fines o alteridad es una estructura de vida compleja y cambiante, el devenir de la existencia se hace dialéctico y en el mejor de los sentidos analéctico, en ese devenir aparece un espacio propio entre el espacio de los otros, un espacio de solidaridad sostenido entre las individualidades. En el sistema racional utilitarista o totalitario, la existencia se presenta como un sistema ontológico clausurado que no permite poros ni libertades extrasistémicas o extratotalizadoras, la existencia es un supuesto normado por las reglas preestablecidas de la totalización, por la exclusión a quien es diferente e incómodo para los intereses del sistema dominante.

La dicotomía entre alteridad y alienación se observa en todos los contextos sociales y en gran medida en la religiosidad, por eso Marquinez Argote intenta trazar las dificultades de las actitudes religiosas enfrentadas al dilema entre racionalidad de medios y racionalidad de fines, en este dualismo entre alteridad y totalidad se plantean los análisis de la religiosidad, así la alienación religiosa en muchos casos como resultado de la pérdida del sentido original del sentimiento del religare entre razón y humanidad, se aprecia la formalidad petrificada de las prácticas religiosas, se percibe el predominio de los procedimentalismos de la ritualidad sobre la esencia de la solidaridad y el mensaje de amor, todo ello

${ }^{1}$ Artículo de reflexión relacionado con la tesina de grado. 
bajo la promesa de una salvación ritual, además de eso hay también prácticas religiosas que ligan la religiosidad con la superstición, lo que implica apartar a las personas de sus problemas cotidianos, sociopolíticos y económicos (Marquinez Argote, 1987, p. 285).

Por supuesto la religión como estructura comunitaria también está inmiscuida en la polaridad de la alteridad y la alienación, incluso ahora que su papel parece restringido, pues desde la época moderna y en esta época contemporánea se ha tratado de reemplazar las tradiciones religiosas míticas por una nueva teología laica, pretendiendo con ello eliminar la dialéctica siempre presente en los humanos entre lo místico y lo lógico. Error profundo y más cuando la teología y la religión tienen mucho que decir con respecto a los hechos relacionados con la dignidad, la técnica, el medio ambiente y los derechos humanos.

El excesivo ritualismo de la religión contemporánea olvida la dimensión metafísica de la religión (Marquinez Argote, 1978, pp. 47-49), la misma que nos dice que somos humanos y como humanos superamos la barrera del inmediatismo natural, para preguntarnos por el más allá de nuestro ambiente natal y solidarizarnos por quienes aún no tienen presencia física, pero a quien reconocemos como otros. La dimensión metafísica permite reconocer a otros como prójimos, como sujetos de la proxemia, independientemente a que si hubieran nacido en nuestro entorno natural, Enrique Dussel plantea la metafísica como un reconocer más allá de nuestro entorno sensible e ir hacia el reconocimiento de los otros como otros, pero no sólo dentro del acostumbrado antropocentrismo sino como pertenecientes a una casa común, donde se comparte con otros seres necesitados de ser reconocidos pero no por eso menos dignos, la religiosidad necesariamente se presenta una apertura metafísica al otro(a) (Dussel, 1994, p. 316).

En ese orden de ideas en un principio el ser humano es un componente de la realidad que al igual que los otros animales se afecta y se determina parcialmente por estímulos, pero no se limita a esa dimensión, por el contrario cavila y crea nuevas escenarios reflexivos, se configura y se personaliza, así sale del límite de la naturaleza inmediata y crea un contexto o mejor se perfila en una realidad que lo fundamenta, crea vínculos con su entorno humano, con su entorno natural y además establece otras dimensiones que están moralmente inscritas en su deseo de comprender y preguntar, lo que le permite una actitud religiosa o de religación de la realidad, el ser humano se hace entonces religioso puesto que pregunta por el sentido de la vida y la existencia; esa religión se toma todos los ámbitos de la cultura porque las preguntas por el entorno y por sí mismo no cesan.

Esta línea aunque es la del papa Francisco no es única de él, pues la comparten tanto la teología como la filosofía de la liberación y muchos movimientos que hoy se consideran críticos al proyecto de la modernidad capitalista; pues todos tienden a presupuestar el papel de la religión en la esfera pública como el de una 
institucionalidad ética que tiene mucho que decir respecto al problema de los derechos humanos, en especial a los que se refieren a la conservación del medio ambiente y la convergencia de la dignidad como principio fundamental de las relaciones de los humanos con la naturaleza, trasladando la idea de la democracia política y social al campo de la democracia y la justicia ambiental.

En consecuencia, el papa Francisco en consenso con las corrientes del cuidado contemporáneas como la que propone Leonardo Boff solicita una conversión ecológica que nace de la espiritualidad propia de la religiosidad, pero esta vez en un religare entre razón y naturaleza, que puede practicarse tanto por los creyentes como por los que no, propuesta que parte no tanto de ideas para proteger el medioambiente sino que se centra en una transformación mística que se comprometa y alimente la pasión por el cuidado del mundo, pero no como un esfuerzo individual sino como un esfuerzo plasmado en solidaridad, formando redes comunitarias que eviten la tentación del consumismo; proponiendo así mismo la creación entre todos de un nuevo modo de vida, donde se privilegie la comunión con el próximo y la proxemia con la naturaleza, siendo esta comunión la base sustancial del uso de la técnica y la ciencia.

Esa religiosidad pretende también salir del drama humano que ha escindido la razón de lo natural, presentando el dilema entre la racionalidad de medios y la racionalidad de fines (o lo que es lo mismo entre totalitarismo y alteridad), lo que se plantea como un asunto de la cultura humana que parece desconocer el equilibrio con su entorno, fomentando una cultura del descarte, que es provocada y a su vez provoca los problemas de la contaminación, Francisco lo nombra como el llevar progresivamente a la "casa común" a ser un depósito de porquería a todos los niveles: Espiritual, Material y Social (Francisco I, 2015 , pp. 18-20). Por supuesto, y por desgracia, esa cultura de descarte ataca la salud púbica en especial a la de los más pobres, de manera especial embiste sobre la calidad ambiental, y acerca a los humanos cada vez más a muertes producidas por enfermedades, epidemias y pandemias.

Así, la imagen que se tiene del mundo en cada época histórica interviene mucho en el tratamiento que la humanidad hace de la naturaleza, por ejemplo, en la tradición aristotélica el movimiento tiene un papel preponderante, todo movimiento es un cambio y todo cambio es movimiento, la exactitud determina la importancia de la investigación natural en la ciencia moderna pero la inexactitud en las ciencias sociales, puesto que las primeras se estudian estáticamente y las segundas por lo general no (Heidegger, 2010, pp. 63-70), lo que no impide que se plantee por ejemplo otro tipo de relación con respecto a las necesidades y a las responsabilidades para con el mundo natural, es obvio que es necesario dar un viraje a la mentalidad que se ha tenido de los sujetos como dominadores de todos los entes del mundo natural. Es evidente que ya los humanos no deben comportarse como los sabios conocedores del mundo extenso ni como 
los investigadores experimentales que han de subyugar la naturaleza y los otros humanos, ahora se hace imperioso una nueva episteme de alteridad, pues el mundo natural obliga a los humanos a mudar la sensibilidad de dominadores a sujetos democráticos en sus constructos ecológicos (70-79).

En consecuencia la doctrina social cristiana de izquierdas, en especial la teología de la liberación (de quien Boff es un gran interprete) pone sobre el tapete la discusión acerca de la dignidad humana y la naturaleza como su agente comunicador, como quiera que se le reconoce a la naturaleza una dignidad dialéctica y se propone para la humanidad un alfabetismo ecológico, pues el conocimiento del entorno cultural ecológico dentro de una ética del cuidado incluye la defensa de la naturaleza, lo que además enriquece las diversas formas de la expresión social y la libertad (Boff, 2002, pp. 108-109).

De esta manera frente a la libertad, las políticas ecológicas se presentan como una oportunidad de convivencia y comunión, es decir, la fraternidad humana construida a partir del discurso religioso ayuda en la construcción del espacio comunicativo que potencia a la solidaridad civil, la construcción de un mundo de la vida y la base directa de la democracia política, social y jurídica (Francisco I, 2015, p. 172). La nueva construcción de un ideario ecológico llama a la fraternidad universal, tanto con los humanos como con la naturaleza, habla de aceptar al hermano como se acepta al sol, al viento y a las nubes, aunque esa aceptación no implique necesariamente control sobre los otros o sobre ese "gran otro" llamado naturaleza, mas bien exige responsabilidad por los demás, la dialéctica debe desembocar en solidaridad, en una ética de fines, honestidad, bondad y fe, con el fin de superar el sometimiento a la violencia y a la crueldad y llegar entre todos a una cultura política y jurídica para el cuidado del medio ambiente.

La nueva visión ética y religiosa define su propuesta como amor social, en la búsqueda de grandes estrategias comunes para superar la marginación en los derechos humanos, para detener la degradación ambiental y alentar la cultura del cuidado tanto para las personas como para la naturaleza, lo que implicaría un reconocimiento de la naturaleza como sujeto comunicativo, casi como la intervención de un mensaje espiritual en las dinámicas sociales del cuidado de la naturaleza (74).

Leonardo Boff privilegia las relaciones sociales con la naturaleza al considerar que de eso se trata el modelo divino, un constante entrelazar de las criaturas que tienden hacia la divinidad, lo que otros llamarían "el ser", ese gran universal que se hace uno con todos, las relaciones se humanizan cuando se entrelazan con la naturaleza y con las criaturas de la naturaleza, la armonía social que se logra es el resultado del rescate de las tradiciones para el compartir con el mundo natural (Boff, 2002, p. 110). 
Pero el punto de partida no es en modo alguno optimista, la teología ambiental considera que la crisis medioambiental no es un problema sólo biológico sino que por el contrario es un problema social, que para superarse debe ser encauzado en otro tipo de esquemas comunicativos y dialécticos que permitan devolver la dignidad a los excluidos, combatir la pobreza y cuidar la naturaleza. Para el papa las relaciones con la naturaleza y sus esquemas ecosistémicos son dialécticas, porque todas las criaturas que conforman el universo humano son armoniosas y constituyen entes o mejor seres comunicativos (Francisco I, 2015, pp. 109).

En consecuencia de acuerdo a lo anterior S.S. Francisco se casa con una propuesta por la edificación de un sistema de protección del medioambiente que esté construido desde la legitimidad, es decir en la certificación de consensos comunicativos para una nueva ética en las relaciones humanas con la naturaleza, el respeto por las libertades, los derechos humanos y su defensa social y jurídica, pero también en una nueva ética basada en idearios diferentes al consumismo y el inmediatismo del lucro y la ganancia; en éste punto parecidos resultan entonces el rol de la religión en la esfera pública y el rol de la ciudadanía como sociedad civil empoderada, esto es la construcción de una nueva estructura en las relaciones con la naturaleza y la ecología.

Igualmente se destaca que el Papa Francisco y Leonardo Boff obviamente no son ingenuos y advierten que es preciso cambiar de inmediato el modelo económico, político y existencial, porque durante mucho tiempo empujado por una mala concepción de la razón moderna, el ser humano tergiversó el ideario moderno y confundió la liberación de la propia alienación o minoría de edad con el dominio de todos los seres naturales, lo que ha traído que la naturaleza (o creación en términos religiosos) reclame por el uso irresponsable que se ha hecho de ella, la cual gracias al expolio de los seres humanos se ha visto enferma de contaminación y desertificación.

La actividad económica del ser humano ha dado al traste con los millones de años que éste usó para tener una armonía con su entorno natural, corriendo el riesgo de destruir la casa común, lo cual constituye la necesidad urgente de combinar y armonizar los progresos científicos y las proezas técnicas con un progreso social y moral (Francisco I, 2015, p. 5). En cierto punto es posible decir que el ideal moderno no se cumple con el trato que se ha dado al mundo en términos ecológicos, pues no ha garantizado el verdadero desarrollo humano y con eso tampoco ha asegurado la salida de la autoculpable minoría de edad que Kant tanto añoró.

En conclusión la teología ecológica busca la transformación humana sobre el trato que se le da al medioambiente, lo cual implica tener en cuenta la necesidad de conectarse con el sistema natural, de tal manera que se entienda como una donación originaria de las cosas, pero también la corrección de las causas que 
estructuran los problemas sociales y ecológicos y los modelos de crecimiento económico que destruyen el medio ambiente, así como la renovación de la cultura que contribuye y soporta la degradación del ambiente (Boff, 2002, pp. 110-111).

Las personas humanas han considerado que la apertura hacia la libertad cultural necesariamente implica un olvido del origen natural, han confundido la libertad con la "emancipación" de lo natural y el individualismo, cuando por el contrario es en la modulación con la naturaleza y es en sociedad donde la libertad se encuentra. La posición de S.S. Francisco y de Leonardo Boff se concreta en un intento por aceptar la comunión con la creación, el prójimo y la divinidad, advirtiendo de cierta manera que se hacen inseparables la justicia con los pobres y la inclusión de la naturaleza como un todo, por eso se propone un trascender del entendimiento del ser diferente al usual, propuesto entre las nociones matemáticas y la experimentación de las ciencias duras, con el fin de crear criterios morales que conecten con la esencia humana.

No se busca con lo dicho volver al romanticismo ingenuo que rechazaba los avances científicos, tampoco prescindir del conocimiento natural, más bien lo que se pretende es el encontrar una nueva relación teórica o social con lo natural, repensar la idea de dominación y esclavitud entre la humanidad y la naturaleza y rehacer el mundo hacia una nueva epistemología y una nueva poética con el entorno. La llamada es a lograr una apertura al estupor y a la maravilla, llevar el lenguaje de la fraternidad y la belleza a nuestra relación con el cosmos, no es la renuncia a los placeres de la vida natural y social, es una renuncia a convertir a los otros y al medioambiente en objeto de explotación y consumo.

La razón de medios de la época mal llamada moderna precisó la necesidad de crear lenguajes lógico matemáticos y darle cabida a la experimentación físico - químicas y biológicas con el fin de entender la manera en que la naturaleza hablaba, pero pronto dicho tipo de investigación se convirtió en un modo de dominio, tanto de la naturaleza como de los demás seres humanos, por eso urge la salida de ésta mentalidad, con el fin de dejar de mirar al mundo como un cuaderno de jeroglíficos a resolver y observarlo como un misterio de belleza, el cual se debe contemplar.

Ahora bien, si el amor es un proyecto revolucionario que no cesa, tampoco debe el espíritu humano cesar en su empeño por salir de la minoría de edad en la que se encuentra con respecto a la naturaleza, pues el creerse dueño de algo que fue dado de sí para todos no es una actitud adulta sino adolescencial y egoísta, es el momento de asumir una nueva responsabilidad para con los otros y ese gran otro que es la naturaleza. 


\section{Referencias}

Boff, L. (2002). El cuidado esencial: ética de lo humano, compasión por la Tierra. Madrid: Trotta.

Dussel, E. (1984). Filosofía de la liberación. Bogotá: USTA.

Francisco I (2015). Carta Encíclica. Laudato Sí. Sobre el cuidado de la casa común. Recuperado de goo.gl/HF8pJr

Heidegger, M. (2010). Caminos de bosque. Madrid: Alianza Editorial.

Marquinez Argote, G. (1987). Filosofía de la religión. Bogotá: USTA. 